\title{
Avaliação físico-química e sensorial de uma bebida à base de suco de laranja adicionada ao soro de leite
}

\author{
Physicochemical and sensory evaluation of a beverage based on \\ orange juice and whey
}

Karen de Fátima Rodrigues Cargnin

Marcio Oliveira Hornes ${ }^{2}$

\section{RESUMO}

Em 2017, foram produzidos no Brasil 511 milhões de litros de sucos concentrados, 1 bilhão de litros de sucos tropicais e néctares e 373 milhões de litros de refrescos, o que comprova o interesse do consumidor por bebidas naturais e de maior apelo nutricional. A utilização do soro de leite nesses produtos qualifica-os e, constitui-se em uma maneira de reduzir o impacto ambiental causado pelo lançamento desse tipo de resíduo ao meio ambiente. Em face disso, buscou-se elaborar bebidas de frutas adicionadas de soro de leite bovino e avaliar físico-química e sensorialmente esses produtos. As bebidas foram elaboradas utilizando três concentrações de soro de leite (40, 50 e 60\%), conforme definido em testes preliminares. Os parâmetros considerados como respostas foram $\mathrm{pH}$, acidez total, acidez volátil, óleos e graxas, umidade, cinzas, proteína, açúcares redutores e açúcares redutores totais, sólidos solúveis e turbidez. A análise sensorial foi realizada mediante o teste de ordenação. A análise dos resultados mostrou que as concentrações dos parâmetros físico-químicos não variaram de forma significativa em relação aos diferentes percentuais de soro de leite. No que se refere à análise sensorial, a bebida contendo $60 \%$ de soro de leite se diferiu significativamente em relação às demais amostras para os atributos sabor e cor. Para o atributo odor, as amostras não apresentaram diferenças significativas entre si. Conclui-se que a adição de soro de leite bovino é uma alternativa viável na elaboração de bebida com suco de laranja, sendo possível a utilização de até $50 \%$ de soro de leite bovino na formulação.

Palavras-chave: Bebida. Soro de leite. Suco de laranja. Formulação. Análise físico-química. Análise sensorial.

\footnotetext{
1 Egressa de Licenciatura em Química do Instituto Federal Farroupilha - Campus São Vicente do Sul | karencargnin2014@gmail.com

2 Instituto Federal Farroupilha - Campus São Vicente do Sul I marcio.hornes@iffarroupilha.edu.br
} 


\title{
Avaliação físico-química e sensorial de uma bebida
} à base de suco de laranja adicionada ao soro de leite

\begin{abstract}
In 2017, 511 million liters of concentrated juices, 1 billion liters of tropical juices and nectars and 373 million liters of soft drinks were produced in Brazil, which proves the consumer interest in natural beverages with greater nutritional appeal. The use of whey in these products qualifies them and constitutes a way to reduce the environmental impact caused by the release of this type of waste to the environment. In view of this, we sought to prepare fruit beverages added with bovine whey and to evaluate these products physically and chemically and sensorially. The beverages were made using three concentrations of whey (40,50 and 60\%), as defined in preliminary tests. The parameters considered as responses were $\mathrm{pH}$, total acidity, volatile acidity, oils and greases, moisture, ash, protein, reducing sugars and total reducing sugars, soluble solids and turbidity. Sensory analysis was performed using the ranking test. The analysis of the results showed that the concentrations of the physical-chemical parameters did not vary significantly in relation to the different percentages of whey. With regard to sensory analysis, the beverage containing $60 \%$ whey differed significantly from the other samples for the flavor and color attributes. For the odor attribute, the samples did not show significant differences between them. It is concluded that the addition of bovine whey is a viable alternative in the preparation of a beverage with orange juice, being possible the use of up to $50 \%$ of bovine whey in the formulation.
\end{abstract}

Keywords: Beverage. Whey. Orange juice. Formulation. Physicochemical characterization. Sensory characterization. 


\section{Introdução}

De acordo com a legislação brasileira vigente, suco de fruta é o líquido límpido ou turvo extraído da fruta fresca, madura e lavada, através de processo tecnológico adequado, não fermentado, de cor, sabor e aroma característicos, submetido a tratamento que assegure a sua apresentação e conservação até o momento do consumo. Os sucos de frutas podem ser obtidos por meio da maceração ou esmagamento por equipamentos apropriados ou apenas espremidos (BRASIL, 2009).

A laranja, juntamente com a uva, melancia e maçã, é uma das frutas com maior produção e potencial para a fabricação de sucos no estado do Rio Grande do Sul (KIST et al., 2017). O suco de laranja é considerado uma das melhores fontes de vitamina $\mathrm{C}$ da dieta, e esse dado atrai consumidores que procuram produtos funcionais para compor uma alimentação saudável (CUNHA et al., 2014).

O soro de leite é obtido através do processamento do queijo, no qual a caseína é insolubilizada no seu ponto isoelétrico pela ação da renina, sendo o líquido remanescente chamado de soro doce. Pode também ser obtido por precipitação ácida, sendo chamado de soro ácido. Os tipos de soro obtidos por esses dois diferentes processos apresentam composições diferentes (OLIVEIRA, 2009; GUEDES et al., 2013). O soro de leite contém, em média, $93 \%$ de água, $5 \%$ de lactose, 0,7 a 0,9\% de proteínas, 0,3 a 0,5\% de gordura, $0,2 \%$ de ácido láctico, 0,034\% de cálcio e 0,043\% de fósforo (OLIVEIRA, 2009; CHEN et al., 2016; TALEBI et al., 2019). A fração proteica contém aproximadamente $50 \%$ de $\beta$-lactoglobulina, $25 \%$ de $\alpha$-lactoalbumina e $25 \%$ de outras frações proteicas (soroalbumina, lactoferrina e imunoglobulina). É fonte de um grande número de minerais, carboidratos e proteínas de alto valor biológico. Além de serem altamente digeríveis, apresentam quase todos os aminoácidos essenciais (principalmente os de cadeia ramificada) em concentrações superiores às recomendações diárias pela Organização Mundial da Saúde (SGARBIERI, 2004; OLIVEIRA, 2009; GANJU \& GOGATE, 2017). As proteínas presentes são fontes importantes de peptídeos bioativos e antioxidantes que exercem efeitos benéficos no corpo humano, como ação anti-inflamatória, eliminação de radicais livres, propriedades antidiabéticas e efeito anti-hipertensivo (PATEL, 2015; MARCONE et al., 2017).

As indústrias de alimentos geram quantidades expressivas de resíduos líquidos que apresentam grande variabilidade na composição química devido às diferentes matérias-primas e tipos de processamento empregados. Esses são caracterizados pelo alto conteúdo de sólidos suspensos totais e compostos facilmente biodegradáveis, como carboidratos e proteínas (COMBATT et al., 2017; GOMES et al., 2017). O lançamento de efluentes, sem o tratamento adequado, pode causar um desequilíbrio ecológico de águas superficiais devido ao crescimento anormal de algas e, por consequência, à diminuição dos níveis de oxigênio resultando assim na morte de peixes e outros organismos aquáticos, fenômeno conhecido como eutrofização (ALBERTONI et al., 2017; BRANDINI et al., 2016). As indústrias de laticínios geram, para cada quilo de queijo, tendo como exemplo o queijo Minas Frescal, entre 9-10 $\mathrm{L}$ de soro, o qual possui uma demanda bioquímica de oxigênio (DBO) de 30 a $60 \mathrm{~g} / \mathrm{L}$ (ANDRADE et al., 2015, GANJU \& GOGATE, 2017).

Vários pesquisadores estão estudando diferentes formas de utilizar o soro de leite em outros produtos, como bolos, refrescos, bebidas lácteas ou até mesmo como fertilizante, o que tem se mostrado como uma excelente alternativa para evitar o descarte no meio ambiente, além de gerar um produto diferenciado, inovador e de alto valor nutricional (BATISTA et al., 2015; MANTOVANI et al. 2015; DÍAZ-RAMIREZ et al., 2016; AMARAL et al., 2018; COUTINHO et al., 2019). Nesse sentido, a utilização do soro de leite bovino em suco de frutas é um bom exemplo de aplicação de proteínas como um incremento do valor nutricional, além de reduzir a poluição ambiental por impedir o seu descarte nos corpos receptores.

Com base nas informações apresentadas, este trabalho teve como objetivo elaborar uma bebida que tem como base o suco de laranja, adicionada de diferentes percentuais de soro de leite bovino, 
assim como avaliá-la quanto ao aspecto físico-químico e sensorial, buscando-se uma bebida com real potencial para produção comercial, enriquecida nutricionalmente com o aproveitamento de um subproduto da indústria láctea, comumente desperdiçado.

\section{Metodologia}

Para o desenvolvimento da pesquisa foram elaboradas bebidas com diferentes concentrações de soro de leite bovino adicionados ao suco de laranja, as quais foram posteriormente analisadas quanto às suas características físico-químicas e sensoriais.

\subsection{Soro de leite}

O soro de leite bovino foi obtido no Setor de Laticínios localizado no Instituto Federal de Educação, Ciência e Tecnologia Farroupilha - IFFar - Campus São Vicente do Sul. O soro de leite é comumente descartado na planta, após a etapa de dessoragem, durante o processo de produção de queijo minas frescal. $\mathrm{O}$ soro foi coletado diretamente do tanque e armazenado sob refrigeração a $5^{\circ} \mathrm{C}$ até o momento da elaboração do suco, sempre realizada no mesmo dia.

\subsection{Elaboração das bebidas}

Os frutos foram colhidos no pomar localizado no IFFar - Campus São Vicente do Sul, Setor de Agricultura I, e encaminhados ao Laboratório da Agroindústria, dentro do mesmo Campus. As frutas com teor de sólidos solúveis acima de 10 Brix foram classificadas e, após selecionadas para a separação das laranjas com sinais visíveis de deterioração. Na sequência, os frutos foram submetidos à lavagem com água corrente em abundância para a retirada de sujidades e sanitizados em solução contendo 150 ppm de cloro livre. Foram lavados novamente e colocados em uma cesta de aço inox para permitir a retirada do excesso de água. Em seguida, as frutas foram submetidas à extração direta em espremedor elétrico convencional dotado de peneira para realizar a filtração.

O soro de leite, previamente pasteurizado, foi misturado diretamente ao suco de fruta de acordo com percentual estabelecido (Tabela 1 ), e as bebidas resultantes envasadas e armazenadas a $8^{\circ} \mathrm{C}$ em garrafas de vidro com capacidade para $1500 \mathrm{~mL}$.

Tabela 1 - Formulações utilizadas no preparo da bebida de laranja adicionada de soro de leite bovino

\begin{tabular}{c|c|c|c|c}
\hline Formulação & $\begin{array}{c}\text { Percentual de soro } \\
\text { na mistura soro e } \\
\text { suco (\%) }\end{array}$ & Soro $(\mathrm{mL})$ & Suco $(\mathrm{mL})$ & Volume final $(\mathrm{mL})$ \\
\hline 1 & 40 & 600 & 900 & 1500 \\
\hline 2 & 50 & 750 & 750 & 1500 \\
\hline 3 & 60 & 900 & 600 & 1500 \\
\hline
\end{tabular}

Fonte: elaborada pelos autores

\subsection{Determinação das características físico-químicas}

As bebidas foram mantidas a $8^{\circ} \mathrm{C}$ por $24 \mathrm{~h}$ e, após, analisadas quanto aos seguintes parâmetros: $\mathrm{pH}$, acidez total, acidez volátil, óleos e graxas, umidade, cinzas, proteína, açúcares redutores, açúcares redutores totais, sólidos solúveis e turbidez. $\mathrm{O}$ pH foi determinado através da medição direta em potenciômetro digital (Marconi, modelo PA 200), previamente calibrado. A acidez total foi determinada através da titulação com $\mathrm{NaOH} 0,1 \mathrm{~N}$, utilizando como indicador a fenolftaleína (IAL, 2008). A 
acidez volátil foi determinada por extração por arraste a vapor, seguida da titulação do condensado com $\mathrm{NaOH} 0,1 \mathrm{~N}$, utilizando como indicador a fenolftaleína (IAL, 2008). Os óleos e graxas foram determinados pelo método de Gerber e o teor de proteína pelo método de Kjeldhal (IAL, 2008). A umidade foi determinada por secagem direta em estufa a $105^{\circ} \mathrm{C}$, após evaporação em banho maria e as cinzas por incineração da amostra em bico de Bunsen e mufla (IAL, 2008). Os açúcares redutores e açúcares redutores totais foram determinados pelo método de Eynon-Lane (IAL, 2008). Os sólidos solúveis foram determinados por medição direta em refratômetro manual (Atago N-1E). A turbidez foi determinada diretamente por leitura em turbidímetro (Tecnopon, modelo TB 1000).

Os parâmetros físico-químicos para cada bebida foram comparados utilizando o teste "t" de student a um nível de significância de 5\% ( $p \leq 0,05)$.

\subsection{Análise sensorial}

Participaram do teste 32 julgadores não treinados, os quais receberam de forma aleatória três amostras codificadas em copos contendo $20 \mathrm{~mL}$ de bebida. Solicitou-se a cada julgador que tomasse um gole de água (à temperatura ambiente) entre uma amostra e outra. As análises foram feitas em cabines individuais e cada julgador recebeu uma ficha para avaliação (Figura 1), solicitando que expressasse sua opinião, ordenando as amostras em ordem crescente de preferência, ou seja, da menos preferida para a mais preferida. Todos os julgadores receberam e assinaram o Termo de Consentimento Livre e Esclarecido (TCLE). O projeto foi aprovado pelo Comitê de Ética em Pesquisa do Instituto Federal de Educação, Ciência e Tecnologia Farroupilha, sob o número de registro CAAE 93628518.2.0000.5574.

Os dados obtidos foram compilados em um software de planilhas e a diferença do somatório das notas para cada nível de preferência foi comparado com a tabela para o teste de ordenação de Newell e MacFarlane (DUTCOSKY, 2007).

Figura 1 - Ficha referente ao teste de ordenação

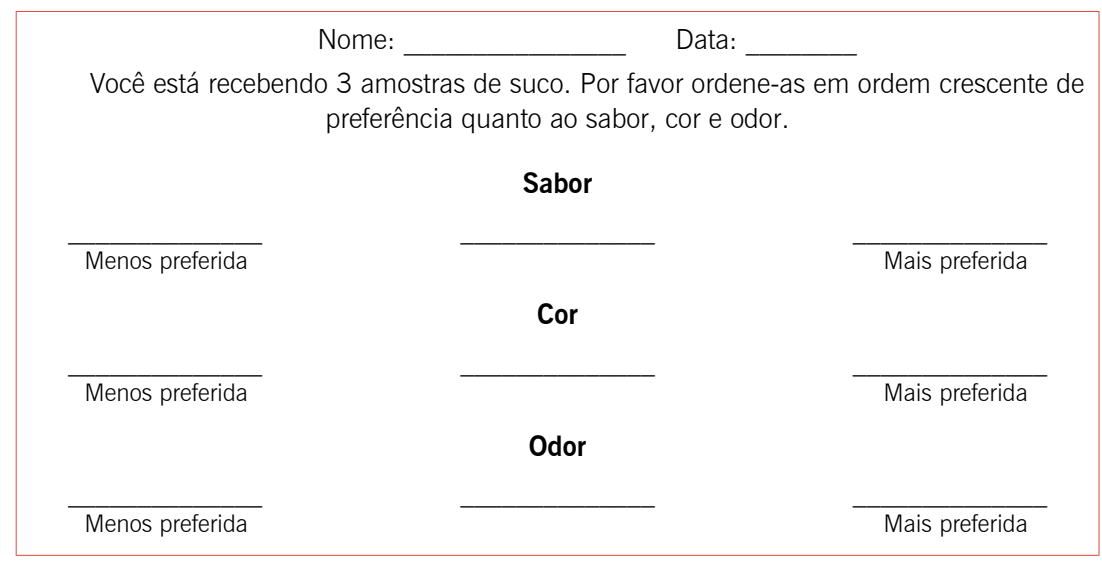

Fonte: elaborada pelos autores

A metodologia adotada para a realização deste trabalho possibilitou atingir os demais objetivos propostos, com a análise e a discussão dos resultados obtidos.

\section{Resultados e discussão}

Uma vez que o suco de laranja foi misturado com um produto de origem animal, verifica-se que as bebidas com 40 e $50 \%$ de soro de leite podem ser consideradas bebidas compostas (Tabela 1). Bebida Composta é definida como aquela obtida pela mistura de sucos, polpas ou extratos vegetais, em conjunto ou separadamente, com produto de origem animal, tendo predominância em sua composição 
de produto de origem vegetal, adicionada ou não de açúcares (BRASIL, 2013). Segundo a Instrução Normativa n. 16 de 23/08/2005, do Ministério da Agricultura, Bebida Láctea é o produto obtido a partir de leite e/ou soro de leite, adicionado ou não de produto(s) ou substância(s) alimentícia(s), gordura vegetal, leite(s) fermentado(s), fermentos lácteos selecionados e outros produtos lácteos, de forma que a base láctea represente pelo menos $51 \%$ massa/massa do total de ingredientes do produto (BRASIL, 2005). Dessa forma, o produto obtido com $60 \%$ de soro de leite, de acordo com a legislação brasileira, não poderia ser classificado como bebida composta, e sim como bebida láctea.

Tabela 2 - Resultados da análise físico-química do suco de laranja enriquecido com soro de leite bovino

\begin{tabular}{l|c|c|c|c}
\hline \multicolumn{1}{c|}{ Parâmetro } & Soro de leite & Suco $+40 \%$ soro & Suco $+50 \%$ soro & Suco $+60 \%$ soro \\
\hline $\mathrm{pH}$ & $6,84 \pm 0,12$ & $3,29 \pm 0,15 \mathrm{a}$ & $3,41 \pm 0,17 \mathrm{a}$ & $3,57 \pm 0,15 \mathrm{a}$ \\
\hline Acidez total & $0,11 \pm 0,02^{*}$ & $0,77 \pm 0,11 \mathrm{a} * *$ & $0,66 \pm 0,09 \mathrm{a} * *$ & $0,55 \pm 0,07 \mathrm{a} * *$ \\
\hline Acidez volátil & 0,009 & $0,005 \mathrm{a}$ & $0,017 \mathrm{a}$ & $0,005 \mathrm{a}$ \\
\hline Óleos e graxas & $0,75 \pm 0,03$ & $0,2 \pm 0,0 \mathrm{a}$ & $0,2 \pm 0,0 \mathrm{a}$ & $0,2 \pm 0,0 \mathrm{a}$ \\
\hline Umidade & $92,58 \pm 1,48$ & $91,25 \pm 0,66 \mathrm{a}$ & $91,24 \pm, 046 \mathrm{a}$ & $94,15 \pm 4,91 \mathrm{a}$ \\
\hline Cinzas & $0,45 \pm 0,03$ & $0,41 \pm 0,01 \mathrm{a}$ & $0,42 \pm 0,01 \mathrm{a}$ & $0,42 \pm 0,01 \mathrm{a}$ \\
\hline Proteína & $1,64 \pm 0,65$ & $1,07 \pm 0,46 \mathrm{a}$ & $1,18 \pm 0,24 \mathrm{a}$ & $1,20 \pm 0,16 \mathrm{a}$ \\
\hline Açúcares Redutores & - & $2,95 \pm 0,71 \mathrm{a}$ & $2,53 \pm 0,78 \mathrm{a}$ & $2,34 \pm 0,96 \mathrm{a}$ \\
\hline Açúcares Redutores & $1,75 \pm 0,00$ & $4,28 \pm 1,93 \mathrm{a}$ & $4,22 \pm 1,88 \mathrm{a}$ & $4,11 \pm 1,81 \mathrm{a}$ \\
\hline Totais & $4,9 \pm 0,1$ & $7,3 \pm 0,5 \mathrm{a}$ & $7,0 \pm 0,5 \mathrm{a}$ & $6,3 \pm 0,6 \mathrm{a}$ \\
\hline Sólidos solúveis & $1169 \pm 175$ & $1170 \pm 57 \mathrm{a}$ & $1181 \pm 65 \mathrm{a}$ & $1121 \pm 64 \mathrm{a}$
\end{tabular}

Acidez Total (mEq/L); Acidez Volátil (mEq/L); Óleos e graxas (\%); Umidade (\%); Cinzas (\%); Proteína (\%); Açúcares Redutores (\%); Açúcares Redutores Totais (\%); Sólidos Solúveis ( ${ }^{\circ}$ Brix); Turbidez (NTU). *Acidez total expressa em g/100 mL de ácido lático. **Acidez total expressa em $\mathrm{g} / 100 \mathrm{~mL}$ de ácido cítrico. * Letras iguais na mesma linha não diferem significativamente $(p \leq 0,05)$ entre si.

Fonte: elaborada pelos autores

Os resultados das análises físico-químicas do soro de leite e suco de laranja com adição de soro de leite estão apresentados na Tabela 2. Os valores de $\mathrm{pH}$ e acidez variaram com o aumento do percentual de soro mas, estatisticamente $(p \leq 0,05)$, essa diferença não foi significativa entre as bebidas adicionadas de soro de leite bovino. A concentração de ácido láctico no soro de leite doce é de $0,1 \%$ p/p (MADRID, 1995), enquanto para o suco de laranja o ácido cítrico, predominante nesse tipo de fruta, compõe entre 0,5-1,1\% p/v (KHANDPUR \& GOGATE, 2016). Dessa maneira, irá atuar como um diluente no suco, com redução da acidez e consequente aumento do $\mathrm{pH}$, de acordo com o acréscimo de soro no suco de laranja. Mesmo com esse efeito de diluição, o pH da bebida ficou próximo aos valores de 3,60-3,80 encontrados por Khandpur \& Gogate (2016) e Paniagua-Martínez et al. (2018) para o suco de laranja in natura, o que é considerada uma importante informação, uma vez que a alta acidez irá exercer um efeito antimicrobiano natural.

0 teor de óleos e graxas não diferiu significativamente $(p \leq 0,05)$ entre os diferentes tratamentos do suco, o que pode ser explicado pelo baixo teor desse componente no soro $(0,75 \%)$ e a consequente distribuição da gordura nas bebidas. Esses valores são inferiores aos encontrados por Guedes et al. (2013), que obtiveram um resultado de $0,7 \mathrm{~g} / 100 \mathrm{~g}$ em uma bebida de graviola adicionada de $65 \%$ de soro lácteo.

A concentração de sólidos solúveis ficou entre 6,3 e 7,3Brix nas bebidas. A redução do teor de sólidos solúveis na bebida final, assim como dos açúcares redutores e açúcares redutores totais, era esperada, uma vez que o soro de leite apresentou um teor médio de $4,9^{\circ}$ Brix, enquanto que o teor 
médio para o suco de laranja natural industrializado está em 9,5-12,5Brix (Quist-Jensen et al., 2016, Paniagua-Martínez et al., 2018, Katsumata et al., 2019). Contudo, essa diferença não foi significativa para as bebidas contendo 40 e $50 \%$ de soro de leite bovino $(p \leq 0,05)$.

Os valores de umidade, cinzas e turbidez não variaram significativamente $(p \leq 0,05)$ entre os diferentes percentuais de soro de leite adicionados ao suco de laranja. Ressalta-se a alta variabilidade nos valores da turbidez, devido aos sólidos dispersos tanto no suco de laranja como no soro de leite, considerando que não foi realizado nenhum tipo de filtração ou adicionado estabilizante, mesmo no produto final, uma vez que se buscava elaborar uma bebida que mantivesse o seu estado natural e com alto teor de sólidos suspensos.

Assim como os demais parâmetros avaliados, a concentração de proteína nas bebidas não variou significativamente a um nível de significância de 5\%. Em todas as amostras, as concentrações proteicas foram superiores quando comparadas com o trabalho desenvolvido por Guedes et al. (2013) em suco de graviola com $35 \%$ de polpa da fruta e adicionado de $65 \%$ de soro de leite bovino, que encontram 0,67\% de proteína, mas inferiores ao estudo dirigido por Baccouche et al. (2013), analisando suco de pera espinhosa enriquecido com soro de leite de bovino, que encontraram 1,29\% de proteína. Esses valores podem não ser expressivos, mas considerando que uma criança na faixa etária de 7-10 anos necessita diariamente 1,0g de proteína por Kg de peso corporal (Janete e Bernardo, citados por Coppini et al., 2017) e, tomando como exemplo uma criança com 8 anos e $15 \mathrm{Kg}$, a sua ingestão deverá ser $15,0 \mathrm{~g}$ de proteína/dia. O consumo de um copo com $200 \mathrm{~mL}$ da bebida de laranja enriquecida com $50 \%$ de soro de leite bovino (Tabela 1) significará $15,7 \%$ da sua necessidade diária de proteína. Cabe lembrar que a ingestão da bebida levará ainda à incorporação de compostos bioativos pela adição de soro de leite ao suco, como aminoácidos de cadeia ramificada (leucina, isoleucina e valina) e peptídeos bioativos que contribuem, por exemplo, para a liberação de inúmeros minerais ( $\mathrm{Ca}, \mathrm{Mg}, \mathrm{Fe}, \mathrm{Zn}, \mathrm{Cr}$, $\mathrm{Ni}$, Co e Se) durante a digestão gastrointestinal (PATEL, 2015; MARCONE et al., 2017).

O teste de Friedman, utilizando a tabela de Newell e Mac Farlane, indica a diferença crítica entre os totais de ordenação, de acordo com o número de tratamentos testados e o número de julgamentos obtidos (Dutcosky, 2007). Os totais de ordenação para as três amostras foram obtidos com base na somatória das notas pelos provadores (Tabela 3). O limite crítico para o número de provadores participantes do teste de ordenação (31 julgadores), segundo a tabela de Newel e Mac Farlane é de 19, através da qual é estabelecido se há diferença significativa entre as amostras no nível de significância de 5\% (DUTCOSKY, 2007).

Tabela 3 - Somatório dos valores obtidos pelo teste de ordenação-preferência dos diferentes sucos testados em função dos atributos sabor, cor e odor

\begin{tabular}{c|c|c|c}
\hline \multirow{2}{*}{ Formulação } & \multicolumn{3}{|c}{ Atributo } \\
\cline { 2 - 4 } & Sabor & Cor & Odor \\
\hline $40 \%$ & $69^{a}$ & $74^{a}$ & $61^{a}$ \\
\hline $50 \%$ & $76^{a}$ & $78^{a}$ & $56^{a}$ \\
\hline $60 \%$ & $47 b$ & $40 b$ & \\
\hline
\end{tabular}

*Letras iguais na mesma coluna não diferem significativamente $(p \leq 0,05)$ entre si. Fonte: elaborada pelos autores

De acordo com a Tabela 3, a formulação contendo $60 \%$ de soro de leite se diferiu significativamente $(p \leq 0,05)$ em relação às demais para os atributos sabor e cor, enquanto que as formulações contendo 40 e $50 \%$ de soro de leite não apresentaram diferença significativa entre si. A formulação da bebida de laranja contendo $60 \%$ de soro apresentou menor preferência, mostrando que acima de 50\% de soro há uma rejeição da mesma. É interessante destacar que, para o atributo cor, o possível motivo para a rejeição da formulação com $60 \%$ de soro de leite é a coloração branca devido à alta concentração 
desse componente, descaracterizando a coloração alaranjada que os consumidores esperam em uma bebida à base de suco de laranja. A adição do corante amarelo crepúsculo seria uma alternativa para atenuar esse problema e deixar a bebida com a coloração laranja característica. Guedes et al. (2013), em um trabalho realizado com diferentes frutas e percentuais de soro de leite, já demonstraram a preferência dos julgadores pela formulação da bebida com cor semelhante ao suco da fruta.

Em todas as formulações, o soro de leite se dispersou de forma eficiente no suco de laranja, sem provocar a formação de fases e resultando em uma bebida homogênea. Essa dissolução se deve ao alto conteúdo de umidade, além do predomínio de açúcares e proteínas (compostos hidrossolúveis) em relação à gordura, que está presente em baixa concentração (CHEN et al., 2016; TALEBI et al., 2019).

Para o atributo sabor, um dos fatores que pode ter contribuído para a rejeição da bebida com $60 \%$ de soro é a acidez. Não houve diferença significativa entre as diferentes formulações testadas (Tabela 2), mas esse parâmetro apresentou valor proporcionalmente inverso à concentração de soro, e a acidez de 0,55 mEq/L pode ter sido insuficiente para agregar um sabor agradável. Além disso, quanto maior o percentual de soro de leite adicionado, maior será a concentração de lactose e sais minerais na bebida, o que também poderá contribuir negativamente para o sabor. Isso não significa que em todas as bebidas compostas sempre haverá uma rejeição com o aumento da concentração do soro de leite, mas que no presente trabalho o suco de laranja não foi suficiente para encobrir os efeitos nocivos do ponto de vista sensorial. Um exemplo disso é o trabalho realizado por Guedes et al. (2013), em que a bebida preferida apresentava-se com $65 \%$ de soro se comparada à escolhida em sexto lugar, com 45\%. Isso evidencia a importância do tipo, concentração e proporção utilizada entre o vegetal e o soro nas características sensoriais da bebida.

Para o atributo odor, as amostras não apresentaram diferenças significativas entre si, em um nível de significância de 5\%. A similaridade entre as bebidas é atribuída ao fato de que o suco de laranja não possui um odor marcante e que, na verdade, os julgadores perceberam em todas as amostras apenas o odor do soro e por isso não indicaram diferença. De fato, Guedes et al. (2013) constataram um escore positivo na bebida de soro e goiaba quando comparada com outras frutas e atribuíram esse resultado ao seu odor mais perceptível.

\section{Conclusão}

A análise e interpretação dos resultados permitiram concluir que as concentrações dos parâmetros físico-químicos não variaram de forma significativa em relação aos diferentes percentuais de soro de leite adicionados às bebidas. Por outro lado, a concentração de soro de leite influenciou na preferência das bebidas formuladas, sendo que aquelas contendo $60 \%$ de soro de leite se diferiram significativamente em relação às demais amostras para os atributos sabor e cor. Para o atributo odor, as amostras não apresentaram diferenças significativas entre si.

Dessa forma, conclui-se que a adição de até $50 \%$ de soro de leite bovino é uma alternativa viável na elaboração de bebidas compostas com suco de laranja.

\section{Agradecimentos}

Os autores agradecem ao Instituto Federal Farroupilha e à FAPERGS pelo apoio financeiro. 


\section{Referências}

ALBERTONI, E. F. et al. Water quality of the São Gonçalo channel, urban and agricultural water supply in southern Brazil. Brazilian Journal of Water Resources, Porto Alegre, v. 22, n.2, janeiro de 2017. Disponível em: http:// www.scielo.br/scielo.php?script=sci_arttext\&pid=S2318-03312017000100208. Acesso em: 11/07/2018.

AMARAL, G. V. et al. Whey-grape juice drink processed by supercritical carbon dioxide technology: Physical properties and sensory acceptance. LWT - Food Science and Technology, v. 92, p. 80-86, junho de 2018. Disponível em: https://www.sciencedirect.com/science/article/pii/S0023643818301348. Acesso em: 09/07/2019.

ANDRADE, L. H. et al. Reuse of dairy wastewater treated by membrane bioreactor and nanofiltration: technical and economic feasibility. Brazilian Journal of Chemical Engineering, v. 32, n. 3, p. 735-747, setembro de 2015. Disponível: < http://www.scielo.br/scielo.php?script=sci_arttext\&pid=S0104-66322015000300011>. Acesso: 27/06/2019.

Baccouche, A. et al. A physical stability study of whey-based prickly pear beverages. Food Hydrocolloids, v. 33, p. 234-244, 2013. Disponível: <https://www.sciencedirect.com/science/article/pii/S0268005X13000891>. Acesso: $11 / 07 / 2018$.

BATISTA, M. A. et al. Desenvolvimento, caracterização e análise sensorial de formulações alimentares com proteínas do soro de leite ou albumina para crianças. Brazilian Journal of Food Technology, v. 18, n. 1, p. 31-41, março de 2015. Disponível: http://dx.doi.org/10.1590/1981-6723.3214. Acesso em: 20/07/2020.

BRANDINI, N. et al. Nutrient behavior in a highly-eutrophicated tropical estuarine system. Acta Limnologica Brasiliensia, Rio Claro, v. 28, e21, 2016. Disponível: http://www.scielo.br/scielo.php?script=sci_arttext\&pid=S2179-975X2016000100316\&lng=en\&nrm=iso >. Acesso em: 20/02/2019.

BRASIL. Ministério da Agricultura, Pecuária e Abastecimento. Instrução Normativa n. 16, de 23 de agosto de 2005. Aprova o Regulamento Técnico de Identidade e Qualidade de Bebida Láctea constante do Anexo desta Instrução Normativa. Brasília, DF: Diário Oficial da República Federativa do Brasil, 2005.

BRASIL. Ministério da Agricultura, Pecuária e Abastecimento. Decreto n. 6.871, de 4 de junho de 2009. Regulamenta a Lei n. 8.918, de 14 de julho de 1994, que dispõe sobre a padronização, a classificação, o registro, a inspeção, a produção e a fiscalização de bebidas. Brasília, DF: Diário Oficial da República Federativa do Brasil, 2009. 39 p.

BRASIL. Ministério da Agricultura, Pecuária e Abastecimento. Instrução Normativa n. 19, de 20 de junho de 2013 Instrução Normativa n. 19, de 20 de junho de 2013. Estabelece em todo território nacional a complementação dos padrões de identidade e qualidade para as seguintes bebidas: refresco, refrigerante, bebida composta, chá pronto para consumo e soda desta Instrução Normativa. Brasília, DF: Diário Oficial da República Federativa do Brasil, 2013. 12 p.

CHEN, G. Q. et al. Removal of lactic acid from acid whey using electrodialysis. Separation and Purification Technology, v. 158, p. 230-237, 2016. Disponível: <https://www.sciencedirect.com/science/article/pii/ S1383586615303853 >. Acesso em: 03/06/2019.

COMBATT, M. P. M. et al. Validação do processo de eletrocoagulação e avaliação da eletrodissolução de eletrodos no tratamento de efluentes de abatedouros de aves. Química Nova, São Paulo, v. 40, n. 4, p. 447-453, maio 2017. Disponível: <http://www.scielo.br/scielo.php?script=sci_arttext\&pid=S0100-40422017000400447>. Acesso em: 12/06/2019. 
COPPINI, L. Z.; SAMPAIO, H.; MARCO, D. Recomendações nutricionais para crianças em terapia nutricional enteral e parenteal. In: JANETE, F. B.; BERNARDO, W. M. Projeto Diretrizes: Associação Médica Brasileira e Conselho Federal de Medicina. Brasília: Conselho Federal de Medicina, 2017. p. 35-50.

COUTINHO, N. M. et al. Chocolate milk drink processed by cold plasma technology: Physical characteristics, thermal behavior and microstructure. LWT - Food Science and Technology, v. 102, p. 324-329, março 2019. Disponível: < https://www.sciencedirect.com/science/article/pii/S0023643818311137>. Acesso em: 09/07/2019.

CUNHA, K. D. et al. Estabilidade de ácido ascórbico em sucos de frutas frescos sob diferentes formas de armazenamento. Brazilian Journal of Food Technology, Campinas, v. 17, n. 2, p. 139-145, junho 2014. Disponível: $<$ http://www.scielo.br/scielo.php?pid=S1981-67232014000200006\&script=sci_abstract\&tlng $=$ pt $>$. Acesso em: 07/11/2018.

DÍAZ-RAMÍREZ, M. et al. Effect of whey protein isolate addition on physical, structural and sensory properties of sponge cake. Food Hydrocolloids, v. 61, p. 633-639, dezembro de 2016. Disponível: <https://www.sciencedirect. com/science/article/pii/S0268005X16302697>. Acesso em: 24/06/2019.

DUTCOSKY, S. D. Análise sensorial de alimentos. Curitiba: Champagnat, 2007.

GANJU, S.; GOGATE, P. R. A review on approaches for efficient recovery of whey proteins from dairy industry effluents. Journal of Food Engineering, v. 215, p. 84-96, dezembro de 2017. Disponível: <https://www. sciencedirect.com/science/article/pii/S0260877417303205>. Acesso em: 27/06/2019.

GOMES, T. M. et al. Supplementation of nutrients for table beets by irrigation with treated dairy effluent. Engenharia Agrícola. Jaboticabal, v. 37, n. 6, p. 1137-1147, dezembro de 2017. Disponível: < http://www.scielo.br/scielo. php?script=sci_arttext\&pid=S0100-69162017000601137> . Acesso em: 12/06/2019.

GUEDES, A. F. L. M. et al. Aproveitamento de soro lácteo na formulação de bebidas com frutas e hortaliças. Arquivo Brasileiro de Medicina Veterinária e Zootecnia, Belo Horizonte, v. 65, n. 4, p.1231-1238, agosto de 2013. Disponível: < http://www.scielo.br/scielo.php?pid=S0102-09352013000400040\&script=sci_abstract\&tlng=pt>. Acesso em: 03/06/2019.

Instituto Adolfo Lutz - IAL. Métodos físico-químicos para análise de alimentos. 4. ed. São Paulo: IAL, 2008.

KATSUMATA, T. et al. Non-destructive evaluation of orange juice based on optical scattering intensities. International Journal for Light and Electron Optics, v. 182, p. 1064-1073, abril de 2019. Disponível: <https:// www.sciencedirect.com/science/article/pii/S0030402618320710 > . Acesso em: 11/07/2018.

KHANDPUR, P.; GOGATE, P. R. Evaluation of ultrasound based sterilization approaches in terms of shelf life and quality parameters of fruit and vegetable juices. Ultrasonics Sonochemistry, v. 29, p. 337-353, 2016. Disponível: $<$ https://www.sciencedirect.com/science/article/pii/S1350417715300511 >. Acesso em: 20/07/2020.

KIST, B. B. et al. Anuário Brasileiro de Fruticultura. Santa Cruz do Sul: Editora Gazeta, 2017.

MADRID, A.; CENZANO, I.; VICENTE, J.M. Manual de Indústrias dos Alimentos. São Paulo, SP: Livraria Varela, 1995. 599 p.

MANTOVANI, J. R. et al. Soro ácido de leite como fonte de nutrientes para o milho. Revista Brasileira de Engenharia Agrícola e Ambiental, v. 19, n. 4, p. 324-329, março de 2015. Disponível: <www.scielo.br/pdf/ rbeaa/v19n4/1415-4366-rbeaa-19-04-0324.pdf>. Acesso em: 09/07/2019. 
MARCONE, S. et al. Milk-derived bioactive peptides and their health promoting effects: A potential role in atherosclerosis. British Journal of Clinical Pharmacology, v. 83, p. 152-162, 2017. Disponível: < https://bpspubs. onlinelibrary.wiley.com/doi/epdf/10.1111/bcp.13002 >. Acesso em: 26/07/2020.

OLIVEIRA, M. N. Tecnologia de produtos lácteos funcionais. São Paulo, SP: Atheneu Editora, 2009. 384 p.

PANIAGUA-MARTÍNEZ, I. et al.

Orange juice processing using a continuous flow ultrasound-assisted supercritical $\mathrm{CO}_{2}$ system: Microbiota inactivation and product quality. Innovative Food Science and Emerging Technologies, v. 47, p. 362-370, junho de 2018. Disponível: < https://www.sciencedirect.com/science/article/pii/S1466856417311815>. Acesso em: 10/07/2019.

PATEL, S. Functional food relevance of whey protein: A review of recent finding and scopes ahead. Journal of Functional Foods, v. 19, p. 308-319, 2015. Disponível: <https://www.sciencedirect.com/science/article/pii/ S1756464615004570>. Acesso em 24/07/2020.

SGARBIERI, V. C. Propriedades fisiológicas-funcionais das proteínas do soro de leite. Revista de Nutrição, v. 17, p. 397-409, 2004. Disponível: <https://www.scielo.br/pdf/rn/v17n4/22889.pdf>. Acesso em 12/06/2019.

QUIST-JENSEN, C. A. et al. Direct contact membrane distillation for the concentration of clarified orange juice. Journal of Food Engineering, v. 187, p. 37-43, outubro de 2016. Disponível: < https://www.sciencedirect. com/science/article/pii/S0260877416301704>. Acesso em: 10/07/2019.

TALEBI, S. et al. Fouling and in-situ cleaning of ion-exchange membranes during the electrodialysis of fresh acid and sweet whey. Journal of Food Engineering, v. 246, p. 192-199, abril de 2019. Disponível: < https://www. sciencedirect.com/science/article/pii/S0260877418304862>. Acesso em: 03/06/2019. 